\title{
Patterns of bird-window collisions inform mitigation on a university campus
}

Natalia Ocampo-Peñuela, R Scott Winton, Charlene J Wu, Erika Zambello, Thomas W Wittig, Nicolette L Cagle

Bird-window collisions cause an estimated one billion bird deaths annually in the United States. Building characteristics and surrounding habitat affect collision frequency. Given the importance of collisions as an anthropogenic threat to birds, mitigation is essential. Patterned glass and UV-reflective films have been proven to prevent collisions. At Duke University's West campus in Durham, North Carolina, we set out to identify the buildings and building characteristics associated with the highest frequencies of collisions in order to propose a mitigation strategy. We surveyed six buildings stratified by size and measured architectural characteristics and surrounding area variables. During 21 consecutive days in spring and fall 2014, and spring 2015, we conducted carcass surveys to document collisions. In addition, we also collected ad hoc collision data year-round and recorded the data using the app iNaturalist. Consistent with previous studies, we found a positive relationship between glass area and collisions. Fitzpatrick, the building with the most window area, caused the most collisions. Schwartz and the Perk, the two small buildings with small window areas, had the lowest collision frequencies. Penn, the only building with bird deterrent pattern, caused just two collisions, despite being almost completely made out of glass. Unlike many research projects, our data collection led to mitigation action. A resolution supported by the student government, including news stories in the local media, resulted in the application of a bird deterrent film to the building with the most collisions: Fitzpatrick. We present our collision data and mitigation result to inspire other researchers and organizations to prevent bird-window collisions. 


\section{Patterns of bird-window collisions inform mitigation on a university campus}

Natalia Ocampo-Peñuela ${ }^{1 *}$, R Scott Winton ${ }^{1}$, Charlene $\mathrm{Wu}^{1,2}$, Erika Zambello ${ }^{1,3}$, Thomas Wittig ${ }^{1}$, Nicolette Cagle $^{1}$

${ }^{1}$ Nicholas School of the Environment, Duke University. Durham, NC, USA.

${ }^{2}$ Ecology \& Environment Inc., Arlington, VA, USA

${ }^{3}$ Okaloosa County, Fort Walton Beach, FL, US

"Corresponding author: no19@duke.edu

1 Abstract 
2 Bird-window collisions cause an estimated one billion bird deaths annually in the United States.

3 Building characteristics and surrounding habitat affect collision frequency. Given the importance of

4 collisions as an anthropogenic threat to birds, mitigation is essential. Patterned glass and UV-

5 reflective films have been proven to prevent collisions. At Duke University's West campus in

6 Durham, North Carolina, we set out to identify the buildings and building characteristics associated

7 with the highest frequencies of collisions in order to propose a mitigation strategy. We surveyed six

8 buildings stratified by size and measured architectural characteristics and surrounding area

9 variables. During 21 consecutive days in spring and fall 2014, and spring 2015, we conducted

10 carcass surveys to document collisions. In addition, we also collected ad hoc collision data year-

11 round and recorded the data using the app iNaturalist. Consistent with previous studies, we found a

12 positive relationship between glass area and collisions. Fitzpatrick, the building with the most

13 window area, caused the most collisions. Schwartz and the Perk, the two small buildings with small

14 window areas, had the lowest collision frequencies. Penn, the only building with bird deterrent

15 pattern, caused just two collisions, despite being almost completely made out of glass. Unlike many

16 research projects, our data collection led to mitigation action. A resolution supported by the student

17 government, including news stories in the local media, resulted in the application of a bird deterrent

18 film to the building with the most collisions, Fitzpatrick. We present our collision data and

19 mitigation results to inspire other researchers and organizations to prevent bird-window collisions.

\section{Introduction}

21 General bird-window collisions 
22 Bird-window collisions are an important source of anthropogenic bird mortality accounting for as many as one billion bird deaths annually in the United States (Klem 1990; Klem 2009a; Loss et al. 2014). Among anthropogenic bird fatalities, window collisions are second only to free-ranging cats (Loss et al. 2015). Birds flying through urban or rural landscapes fail to recognize windows as barriers and often collide with them due to glass transparency or reflectivity (Klem 1989). Window collisions are an additional threat for birds that already face natural dangers like predation, disease, starvation, inclement weather, and the cost of long distance migration (Klem 2014). Although it is uncertain whether window collisions are a major cause of the declining trends in some North American bird populations (Arnold \& Zink 2011; DeSante et al. 2015), mortality due to collisions accounts for an annual loss of 2-9\% of the total estimated North American bird population (Loss et al. 2014).

34 All buildings do not pose an equal threat to birds. From previous studies, glass area of a building has been shown to be the most important feature explaining collisions (Borden et al. 2010; Cusa et al. 2015; Hager et al. 2013). Building height also plays a role. Low and medium-rise buildings, such as those found on a university campus, account for 44 and $56 \%$ of total collisions in the United States, respectively (Loss et al. 2014).

The area surrounding a building is also thought to influence the amount of bird-window collisions by attracting birds to adjacent vegetation or available water sources (Hager \& Craig 2014; Klem 1989; Klem 2014). This finding may not apply in all contexts; for example, Borden et al. (2010) found that the presence of trees near buildings had no effects on collision presence and frequency.

44 While many bird species have been documented as window collision victims, differences in habits 45 and behavior cause some to be far more susceptible than others. Studies in North America have 
46 found that $90 \%$ of collisions occur during spring and fall migration (Borden et al. 2010). Passerines

47 that migrate at night, such as warblers and sparrows, collide with windows frequently (Arnold \&

48 Zink 2011; Gelb \& Delacretaz 2006; Klem 1989) because they must traverse many stepping stones of

49 unfamiliar habitat in transit between breeding and wintering grounds. Among the migrants, forest

50 understory species, accustomed to flying low and through restricted space between trees, such as

51 thrushes of the genus Catharus, Wood Thrush (Hylocichla mustelina), Ovenbird (Seiurus aurocapilla)

52 and hummingbirds, are among the most common collision victims (Blem \& Willis 1998; Klem 2014).

53 The disproportionate effect of window-collisions on migratory species is particularly noteworthy

54 given that $50 \%$ of North American migrants have declined by at least $50 \%$ over the past 50 years

55 (Robbins et al. 1989).

56 Mitigation opportunities

57 Given the importance and frequency of window collisions (Loss et al. 2015), mitigation options have

58 been both gaining popularity and championed by urban conservationists and architects.

59 Moral/ethical implications notwithstanding, the prevention of collision-caused bird deaths is

60 arguably necessary in order to comply with the Migratory Bird Treaty Act of 1918 and the

61 Endangered Species Act of 1973 (Klem 2009a; Klem \& Saenger 2013). There is a wide variety of bird

62 deterrent techniques used on windows, including: glass with etched or sandblasted patterns, fritted

63 glass displaying opaque patterns on the outer surface, and UV-reflective films. This last solution has

64 the most potential for widespread application, but in order for it to be effective it must reflect 20-

$6540 \%$ of incipient radiation between 300 and400 nm (Klem 2009b), and to date this solution has yet

66 to be systematically tested at the building scale. Patterns that divide the clear space of windows have

67 been proven effective at deterring window collisions when placed no more than $10 \mathrm{~cm}$ apart (Klem

68 1990; Klem 2009b).

69 Purpose 
70 The purpose of this study was to investigate the patterns of bird-window collisions at Duke

71 University's campus in Durham, North Carolina. We set out to identify the buildings and building

72 characteristics associated with the highest frequencies of bird-window collisions on campus.

73 Unlike many research projects, this one was carried out with advocacy in mind. A fundamental goal

74 of this study was to generate an evidence-based foundation from which we could advise Duke

75 University on the scope of bird death on campus, and how it might best be mitigated. Here, we

76 present results on the bird-window collision data, and the resulting mitigation action. If similar

77 projects were to be implemented en masse across the thousands of North American campuses, the

78 aggregate conservation benefit for birds would be substantial. In addition to such direct

79 conservation benefits, the data generated would greatly improve uncertain estimates of bird-

80 window collision mortality and understanding of associated landscape and phenological factors

81 involved.

\section{Methods}

\section{Study area}

84 The study was conducted at Duke University's West Campus located in Durham, North Carolina,

85 United States (Figure 1). Construction of the campus started in 1924 and buildings continue to be

86 added to the 200 existing structures. The suburban campus spans $34 \mathrm{~km}^{2}, 29 \mathrm{~km}^{2}$ of which are

87 forested. West Campus has a predominantly gothic architecture, though newer buildings include

88 elements of modern construction such as large windows for natural light, multiple wings, and as

89 many as four stories. Starting in 2000, Duke University's administration decided that all new

90 buildings and major renovations would be Leadership in Energy and Environment Design (LEED ${ }^{\mathrm{TM}}$ )

91 certified, with a goal of earning at least LEED ${ }^{\mathrm{TM}}$ Silver status for each (Campus Sustainability

92 Committee 2015). 
93 We selected 6 buildings for the study, stratifying by size: Fitzpatrick Center for Interdisciplinary

94 Engineering Medicine and Applied Sciences (Fitzpatrick), French Family Science Center (French),

95 Penn Pavilion (Penn), Schwartz-Butters Athletic Center (Schwartz), The Perk, and Law School

96 extension (Law extension). Small buildings were $<2500 \mathrm{~m}^{2}$ (The Perk, Law extension), medium sized

97 buildings were between $2500 \mathrm{~m}^{2}$ and $4500 \mathrm{~m}^{2}$ (Schwartz, Penn), and large buildings were between

$9825000 \mathrm{~m}^{2}$ and $32000 \mathrm{~m}^{2}$ (French, Fitzpatrick). All buildings except Schwartz are LEED ${ }^{\mathrm{TM}}$ certified.

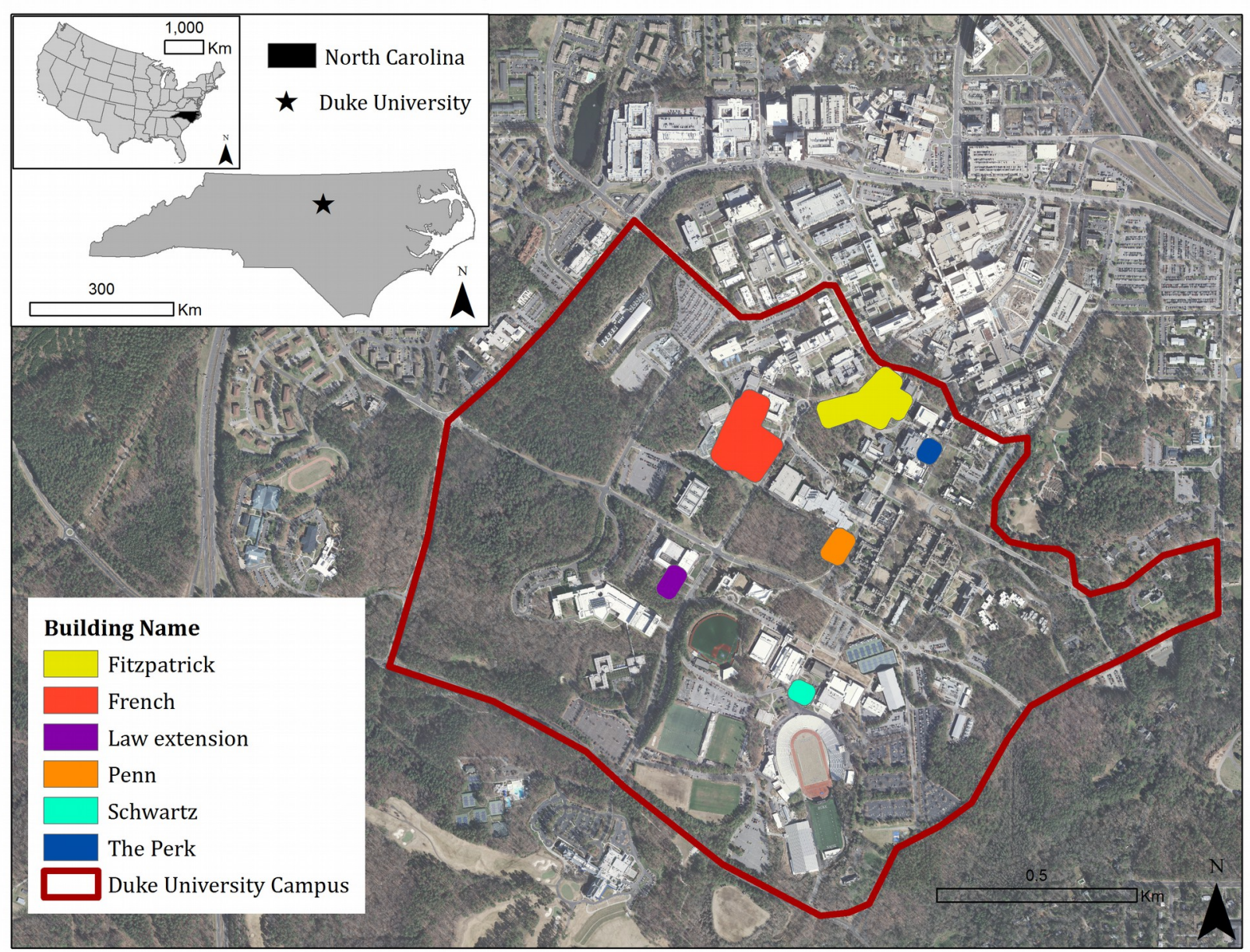

99 Figure 1. Study area. Upper left corner shows the location of the campus in the United States, and

100 within the state of North Carolina. Main panel shows Duke University's West campus and the six

101 study buildings. Background image source: (Duke University Facilities Management Department

102 2012). 
104 We conducted three carcass surveys during peak migration periods in spring and fall 2014, and 105 spring 2015 following methods described by Hager \& Cosentino (2014). We surveyed the 6 study 106 buildings between 1400 and 1600 hrs every day for 21 consecutive days. Before the 21-day survey, 107 we picked up all the accumulated carcasses at each building during a clean-up survey, so all 108 buildings started the survey period with zero carcasses. Spring surveys were between April $1^{\text {st }}$ and $10921^{\text {st }}\left(\right.$ clean up March $\left.31^{\text {st }}\right)$ and the fall survey ran from September $22^{\text {nd }}$ to October $12^{\text {th }}$ (clean-up 110 September $\left.21^{\text {st }}\right)$. We conducted surveys daily to minimize imperfect detection due to carcass 111 removal by scavengers (Hager et al. 2012).

112 During each survey, two observers walked the entire perimeter of each building twice, at a constant 113 speed $(1 \mathrm{Km} / \mathrm{hr})$, looking for carcasses in a 2-m search swath from the building wall. All carcasses or 114 feather piles were recorded, collected, and deposited in a freezer for identification confirmation 115 (pursuance of Federal Fish and Wildlife Permit MB49165B-0). Some carcasses from the surveys 116 were used for teaching purposes at Duke University, while most of the carcasses were given to the 117 North Carolina Museum of Natural Sciences in Raleigh, NC. We identified all complete carcasses to 118 species, but we left some feather piles unidentified due to uncertainty. Following the data collection 119 protocol proposed by Hager \& Cosentino (2014), we recorded data for all surveys, including those in 120 which no birds were found.

121 Although we only conducted standardized surveys during peak migration times, we collected 122 incidental collision data year-round using the smartphone app and webpage iNaturalist (Ueda et al. 123 2015). Since these data are not standardized, we only used these incidental reports for documenting 124 species richness in bird-window collisions. We only used standardized survey data for all analyses of 125 abundance.

\section{Buildings and surrounding area}


127 We collected the following data on building traits: floor space $\left(\mathrm{m}^{2}\right)$, building height $(\mathrm{m})$, total

128 window area $\left(\mathrm{m}^{2}\right)$, percentage of window area to wall surface (\%), LEED ${ }^{\mathrm{TM}}$ certification, and

129 presence of a pattern on the glass that could act as bird deterrent.

130 We used the high resolution ( $1 \mathrm{~m}$ ) land cover map for Durham produced by the US Environmental

131 Protection Agency (2013) to classify the buildings' surrounding area into three main classes: grass,

132 forest, and impervious. We created land cover thresholds based on percent cover within a 25-m

133 radius. We defined forest and impervious surface as those areas with at least $80 \%$ coverage in the

$13425 \mathrm{~m}$ range. Grass had a lower threshold of $25 \%$. With the classified landcover map, we calculated

135 the percentage of area covered by grass, forest, and impervious surfaces within a 50-m buffer

136 around the study buildings.

137 Because of a small sample size of just six buildings and because two of the sampled buildings

138 dominated the others with respect to total collisions and percent glass area, conventional statistical

139 tests were not appropriate for our building attribute data. Instead, we discuss qualitatively the

140 factors that appear to be associated with collision frequency and drive the outliers.

\section{Resolution and media coverage}

142 Resolutions are an advocacy tool that allows a community to call attention to an issue and suggest

143 action from the administration. At Duke, the Graduate and Professional Student Council (GPSC) is an

144 important organization for communicating student needs to University administrators. After two

145 seasons of surveys, we wrote a resolution accounting for the documented bird-window collisions on

146 campus to date, and asking Duke University administrators to take action to mitigate bird-window

147 collisions on campus. We presented the resolution to the GPSC General Assembly, which represents

148 more than 8000 students. The resolution passed unanimously and was sent to all Duke University

149 high level administrators, trustees, and academic deans. 
150 We also agreed to interviews with journalists from the Duke Chronicle, the Raleigh News and

151 Observer, WNCN (local NBC news affiliate), and WRAL (local CBS news affiliate). In addition to the

152 extensive local media coverage, the story of bird-window collisions was the subject of blogs hosted

153 by the Nicholas School of the Environment, the American Birding Association, and Glass Magazine

154 (Supplementary data 1).

\section{Results}

156 The buildings with the most glass area, highest percent glass area, and high surrounding forest cover

157 tended to kill the most birds (Table 1, Figure 2). The building with the largest glass area, $57 \%$ glass

158 cover and 33\% surrounding forest cover, Fitzpatrick, caused 61 of the $86(71 \%)$ collisions detected

159 during standardized surveys (Figure 2, Figure 3A-B). A building with similar amount of glass area

160 but with just $27 \%$ of its façade made of glass and little forest cover, French, yielded just 10 collisions

161 (11\%), making it the second-most-deadly building of the survey (which it shares with the much

162 smaller Law Extension). The only building in the study with bird deterrent glass, Penn, caused just

163 two window collisions and was the least deadly building in terms of collisions per glass area despite

164 being similar to a glass box ( $97 \%$ glass cover), and in a heavily forested setting ( $76 \%$ surrounded by

165 forest) (Figure 3C-D). Other buildings that caused two or fewer collisions were the two buildings

166 with smallest amount of glass coverage and low surrounding forest cover, Schwartz and The Perk.

167 Schwartz is the only building in the study that is not LEED ${ }^{\mathrm{TM}}$ certified.

168 Table 1. Building traits, surrounding area characteristics and collisions results for six buildings at

169 Duke University's West campus. Percentage impervious, grass, and forest are based on a 50m buffer

170 around the building. Days with collisions and total collisions are based on collisions detected during

17163 days of standardized surveys in the fall and spring of 2014 and spring of 2015. LEED ${ }^{\mathrm{TM}}$ :

172 Leadership in Energy and Environmental Design Certification. 


\begin{tabular}{|c|c|c|c|c|c|c|c|c|c|c|c|c|}
\hline \multirow[b]{2}{*}{ Building name } & \multicolumn{4}{|c|}{ Building traits } & \multicolumn{4}{|c|}{ Surrounding area } & \multicolumn{4}{|c|}{ Collision results } \\
\hline & $\begin{array}{c}\text { Floorspace } \\
\left(\mathbf{m}^{2}\right)\end{array}$ & $\begin{array}{c}\text { Glass area } \\
\left(\mathrm{m}^{2}\right)\end{array}$ & $\begin{array}{c}\text { Glass coverage } \\
(\%)\end{array}$ & LEED $^{\mathrm{TM}}$ & $\begin{array}{l}\text { Impervious } \\
\text { surface }(\%)\end{array}$ & $\begin{array}{c}\text { Grass } \\
(\%)\end{array}$ & $\begin{array}{c}\text { Forest } \\
(\%)\end{array}$ & $\begin{array}{l}\text { Distance to } \\
\text { forest patch } \\
\text { (m) }\end{array}$ & $\begin{array}{l}\text { Clean-up } \\
\text { survey }\end{array}$ & $\begin{array}{l}\text { Days with } \\
\text { collisions }\end{array}$ & $\begin{array}{l}\text { Collisions/ } \\
100 \mathrm{~m}^{2} \text { glass }\end{array}$ & $\begin{array}{c}\text { Total } \\
\text { collisions }\end{array}$ \\
\hline Fitzpatrick & 30860 & 1883 & 57 & Silver & 20 & 47 & 33 & 34 & 19 & 25 & 3.24 & 61 \\
\hline French & 27282 & 1716 & 27 & Silver & 60 & 39 & 1 & 102 & 2 & 8 & 0.58 & 10 \\
\hline Schwartz & 4040 & 148 & 12 & - & 95 & 5 & 0 & 166 & 0 & 2 & 1.35 & 2 \\
\hline Penn* & 2322 & 437 & 98 & Silver & 18 & 6 & 76 & 0 & 0 & 1 & 0.46 & 2 \\
\hline Law extension & 604 & 199 & 56 & Green & 41 & 21 & 39 & 0 & 3 & 2 & 5.03 & 10 \\
\hline The Perk & 416 & 42 & 18 & Green & 74 & 13 & 14 & 218 & 0 & 1 & 2.38 & 1 \\
\hline & * Building $\mathrm{w}$ & vith pattern & on glass & & & & & & & & & \\
\hline
\end{tabular}

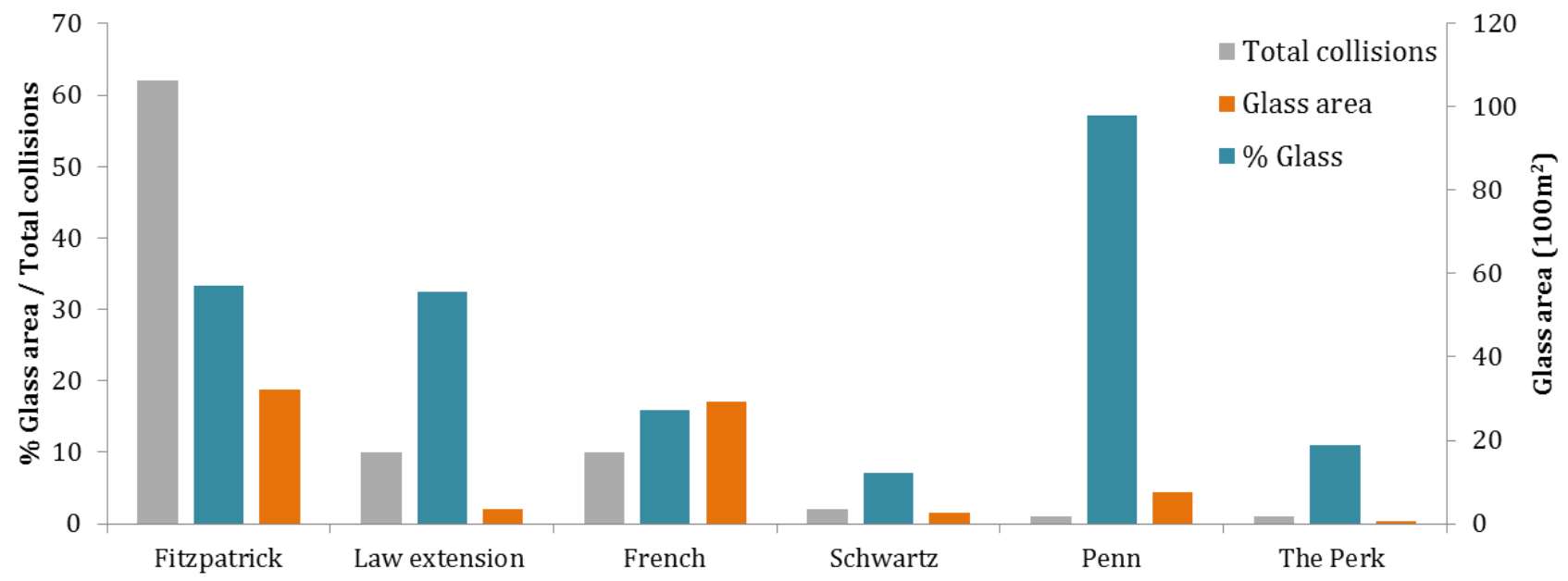

173 Figure 2. Glass metrics and bird-window collisions detected during 3 seasons of 21-day surveys of

174 six buildings at Duke University's West campus in Durham, NC. Penn is the only building in the study

175 with fritted glass known to deter birds. 


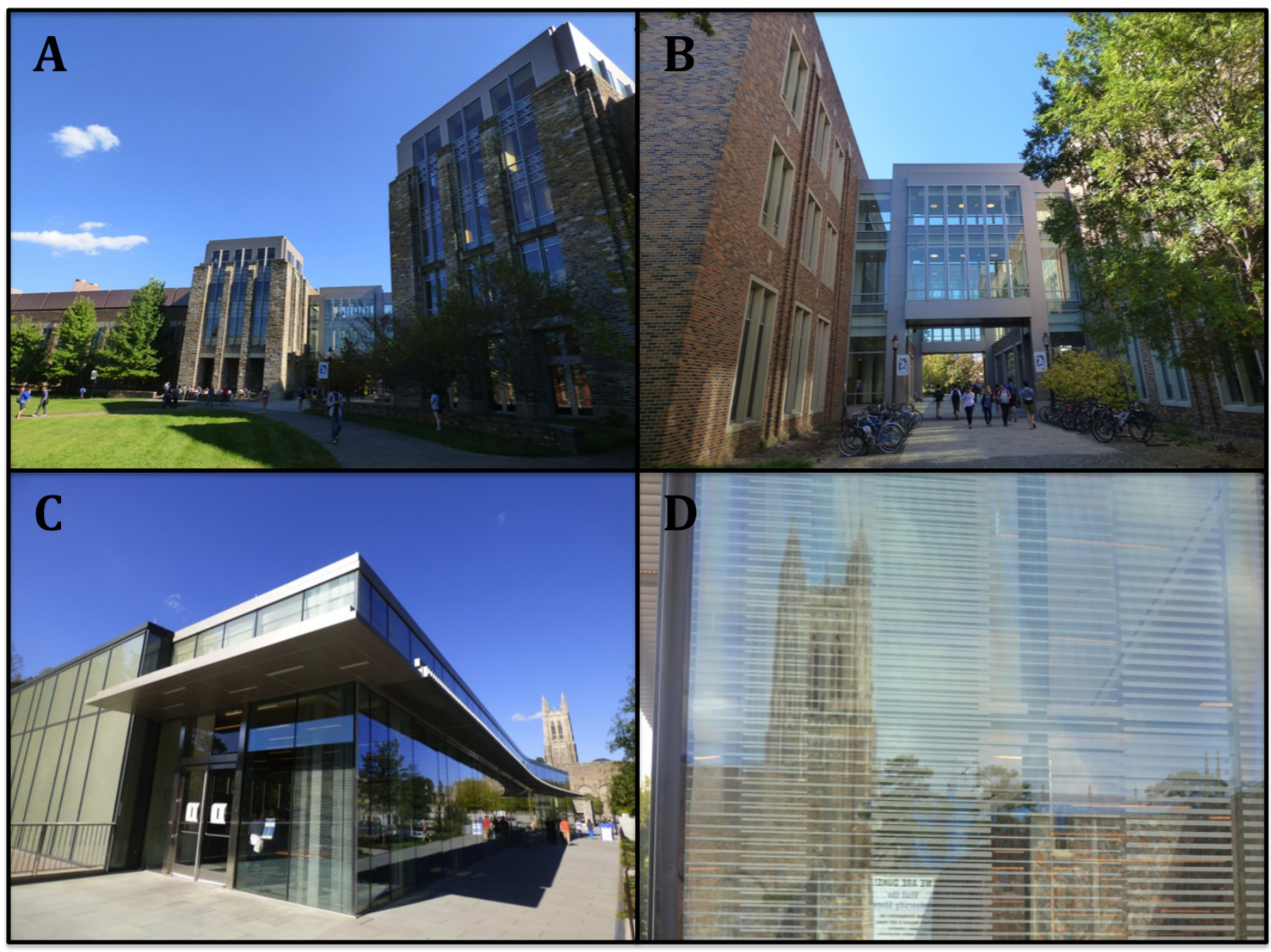

176 Figure 3. A-B: Fitzpatrick, the buildings with the highest bird-window collision frequency at Duke

177 University. C-D Penn, the only building with bird deterrence patterns at Duke University.

178 In addition to the carcasses discovered during our 21-day surveys, we documented 102 incidental

179 collisions throughout the study period across the entire Duke University campus, as well as 33

180 collisions found during carcass cleanups prior to each survey period. Incidental collisions were most

181 frequently documented during important months for bird migration (April, September, and October)

182 (Figure 4). 


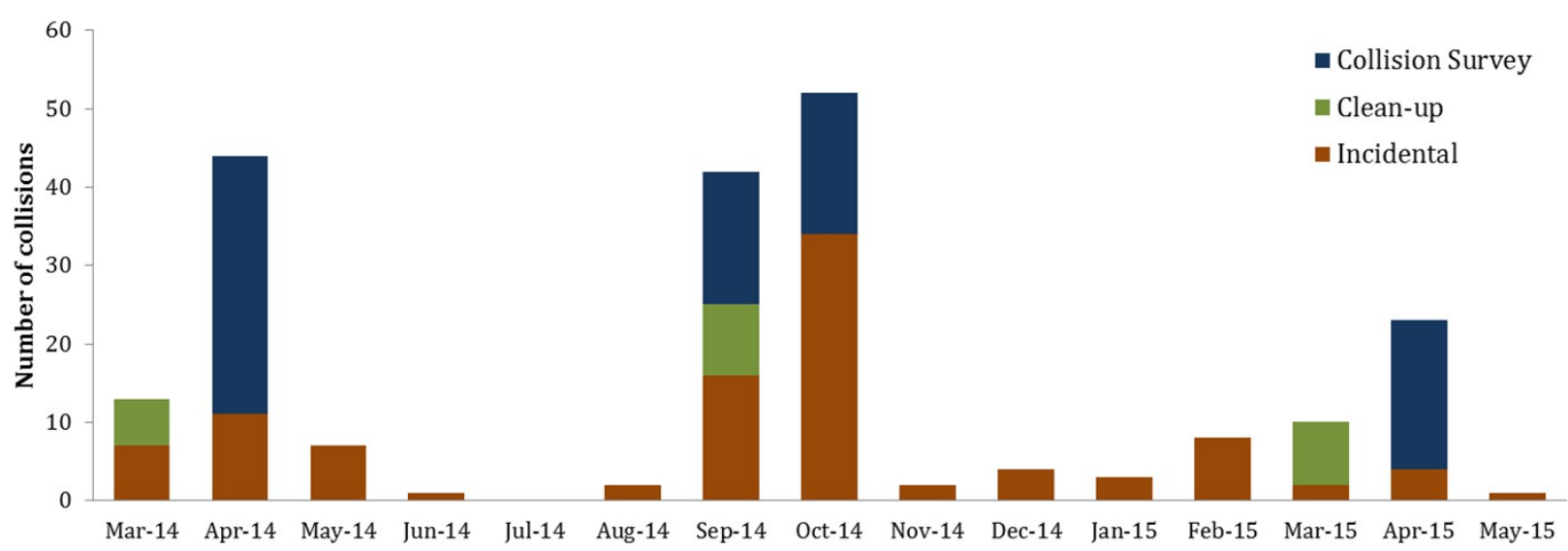

183 Figure 4. Seasonal distribution of bird-window collisions binned by month at Duke University's

184 West campus in Durham, NC.

185 We documented 41 species as collision victims, 31 of which (76\%) were migratory. Five species 186 collided with windows five or more times during the standardized carcass surveys: Cedar Waxwing 187 (Bombycilla cedrorum)(11), Ovenbird (Seiurus aurocapilla) (7), American Goldfinch (Spinus tristis) 188 (7), Northern Cardinal (Cardinalis cardinalis) (6), and Tufted Titmouse (Baeolophus bicolor) (5). 189 Incidental collisions showed a slightly different set of species with the most collisions: Ruby190 throated Hummingbird (9), American Goldfinch (8), Yellow-bellied Sapsucker (6), and Hermit 191 Thrush (6) (Table 2).

192 Table 2. List of species observed as window collision victims at Duke University's West campus 193 during 2014 and 2015. Migratory status from Cornell Lab of Ornithology (2015), complemented 194 with local observations. 


\begin{tabular}{|c|c|c|c|c|c|c|c|c|c|c|c|c|}
\hline \multirow[b]{2}{*}{ Order } & \multirow[b]{2}{*}{ Family } & \multirow[b]{2}{*}{ Common Name } & \multirow[b]{2}{*}{ Scientific Name } & \multirow[b]{2}{*}{$\begin{array}{l}\text { Migratory } \\
\text { status }\end{array}$} & \multirow[b]{2}{*}{$\begin{array}{l}\text { \# Incidental } \\
\text { Collisions }\end{array}$} & \multicolumn{4}{|c|}{2014} & \multicolumn{2}{|c|}{2015} & \multirow[b]{2}{*}{$\begin{array}{c}\text { Survey } \\
\text { total }\end{array}$} \\
\hline & & & & & & $\begin{array}{c}\text { Pre-survey } \\
\text { Spring }\end{array}$ & $\begin{array}{l}\text { Survey } \\
\text { Spring }\end{array}$ & $\begin{array}{c}\text { Pre- } \\
\text { survey Fall }\end{array}$ & $\begin{array}{c}\text { Survey } \\
\text { Fall }\end{array}$ & $\begin{array}{c}\text { Pre-survey } \\
\text { Spring }\end{array}$ & $\begin{array}{l}\text { Survey } \\
\text { Spring }\end{array}$ & \\
\hline Solumhiformes & Colımhidae & Mnurning Dnve & 7enaidn marrnura & Resident* & 1 & & 1 & & & & & 1 \\
\hline Anndifnrmes & Tranhilidae & Ruhy-thrnated Humminghird & Arrhilarhusenluhris & Migrant & 9 & & & & 1 & & 2 & 3 \\
\hline Pinifnrmes & Piridae & Dnwerny Whodnerker & Pirnidoe nuhoerons & Recident & 1 & & & & & & & $n$ \\
\hline Piriformes & Piridae & Narthern Flirker & Colantesauratus & Resident* & 1 & & & & & 1 & & $n$ \\
\hline Piriformes & Picidae & Vellnur-hellied Sansurker & Snhyranicus varius & Migrant & 6 & & & & 1 & & & 1 \\
\hline Pirifnrmes & Piridae & Red-hellied Wondnerker & Melanernessarnlinus & Resident & 3 & & & & & & & $n$ \\
\hline Passeriformes & Virennidae & Red-eyed Viren & Viren nlivareus & Migrant & 2 & & & & 3 & & & 3 \\
\hline Passeriformes & Paridae & Tufted Titmouse & Rnonlnnhus hirnlar & Resident & 1 & 1 & 5 & & & & & 5 \\
\hline Passerifnrmes & Sittidae & White-hreaster Nuthatch & Sitta rarnlinensis & Resident & & & 1 & & & & & 1 \\
\hline Pasceriformas & Trnoglndytidap & Carnlina Wren & Thrynthomicludnvirianus & Resident & 1 & & & & & & & $n$ \\
\hline Passeriformes & Regululidae & Finlden-rrowrned Kinglet & Regulus satrana & Midrant & 3 & & & & & & & $n$ \\
\hline Passeriformes & Regillidae & Ruhy-rrnwrned Kinglet & Reguluscalendula & Miorant & & & 1 & & & & 1 & ? \\
\hline Passeriformes & Turdidae & American Rnhin & Turdus mingratnrius & Migrantt & 1 & 1 & 1 & & & ? & 2 & 3 \\
\hline Passeriformes & Turdidae & Veery & Cathamis fussessens & Miorrant & & & & 1 & & & & $n$ \\
\hline Passeriformes & Turdidae & firay-rheeked Thrush & Sathamisminimus & Miorant & 1 & & & & 1 & & & 1 \\
\hline Pascerifnermes & Turdidae & Hermit Thrush & Cathamis auttatus & Migrant & h & & & & & 1 & & $n$ \\
\hline Passeriformes & Turdidae & Wond Thrush & Hụln richla mustolina & Migrant & 1 & & & 1 & 3 & & & 3 \\
\hline Passeriformes & Turdidae & Swrainson's Thrush & ratharus ustulatus & Migrant & & & & 1 & & & & $n$ \\
\hline Passeriformes & Mimidae & Brnwarn Thrasher & Tnxnstoma mifium & Resident* & & 1 & & & $?$ & & & 2 \\
\hline Passeriformes & Mimidae & Northern Markinohird & Mimus nnlvalnttas & Resident & & & & & ? & & & 2 \\
\hline Passeriformes & Mimidae & firay Cathird & Dumotella ramalinensis & Miorrant & 4 & & & 2 & 3 & & & 3 \\
\hline Passeriformes & Rnmhyrillidae & Cedar Waswaring & Romhyerilla rednmım & Migrant & 2 & 1 & 11 & & & & & 11 \\
\hline Passeriformes & Parulidar & American Redstart & Setanhingan ruticilla & Migrant & 2 & & & & 1 & & 2 & 3 \\
\hline Pacseriformes & Parnlidap & Blark-throated Rlue Warhler & Dondrnien rnomiloseons & Migrant & & & & & 1 & & & 1 \\
\hline Pasceriformes & Parulidap & Rlark-throated fireen Warhler & Dondraira virons & Migrant & & & & & 1 & & & 1 \\
\hline Passeriformes & Parulidae & Cane Mav Warhler & nendraicatiarina & Migrant & $?$ & & & & & & & $n$ \\
\hline Pasceriformes & Parnllidap & Chestnut-sided Warhler & Dendraisa nensyluanier & Migrant & 1 & & & & & & & $n$ \\
\hline Passeriformes & Parulidae & Snmmon Vellnwthrnat & Genthlynistrichas & Midrant & 4 & & & 1 & & & & $n$ \\
\hline Passeriformes & Parullidar & Ovenhird & Seiumisauraranilla & Migrant & 1 & & & 1 & ? & & 4 & h \\
\hline Passeriformes & Parnllidap & Vellnw-rumned Warhler & Dondrnica rnmanatn & Migrant & 4 & & 1 & & & & & 1 \\
\hline Passeriformes & Fmherizidae & White-thrnated Snarrnw & 7nnntrichin alhisnllis & Migrant & 2 & & 1 & & & & & 1 \\
\hline Pasceriformes & Fmherizidae & Fastern Towhep & Piniln orvthronhthalmus & Resident* & 3 & & & & & & & $n$ \\
\hline Pasceriformes & Fmherizidae & SondSnarrow & Molnsniza molndia & Recident* & 4 & & & & & & 1 & 1 \\
\hline Passeriformes & Fmherizidae & Swamn Snarrnw & Molnșiza genraiana & Miorant & 3 & & & & & & 1 & 1 \\
\hline Passeriformes & Fmherizidae & Dark-eyed Juncn & Tunen hyemalis & Migrant & 3 & & & & & & 1 & 1 \\
\hline Passeriformes & Emherizidae & Fnx.Snarrnwr & Passerella iliasa & Migrant & 1 & & & & & & & $n$ \\
\hline Passeriformes & Cardinalidae & Indiogn Runting & Passerina ryanen & Migrant & 1 & & & & & & & $n$ \\
\hline Pascorifnermes & Cardinalidae & Narthern Fardinal & Cardinalis rardinalis & Resident & 2 & & 2 & & ? & 1 & 2 & 6 \\
\hline Pasceriformes & Cardinalidap & Roce-hreastedfirncheak & Phourtirucludnvirianus & Midrant & 1 & & & 1 & & & & $n$ \\
\hline Passeriformes & Pardinalidae & Srarlet Tanader & Piranga nlivarea & Migrant & 1 & & & & & & & $n$ \\
\hline \multirow[t]{3}{*}{ Pasceriformes } & Fringillidae & Americanfinldfinch & Carduolis tristic & Migrantt & 8 & & & & 6 & 1 & 1 & 7 \\
\hline & & Inidentified & Inidentified & & 12 & 2 & 7 & 1 & 6 & 2 & 3 & 16 \\
\hline & & & Total & 31 & 98 & 6 & 31 & 9 & 35 & 8 & 20 & 86 \\
\hline
\end{tabular}

195 After collecting these collision data and observing Fitzpatrick's dominant contribution to bird-

196 window collisions, our group, supported by the Graduate and Professional Student Council, led an

197 effort to retrofit Fitzpatrick with bird deterrent patterns. Duke University facilities management

198 department installed a bird deterrent film on several sections of glass façade at Fitzpatrick. Two

199 glass passageways (Figure 5A) and other windows we identified as dangerous for birds, were

200 retrofitted with a $2.5 \mathrm{~cm} x 2.5 \mathrm{~cm}$ dotted pattern film called Feather Friendly ${ }^{\circledR}$ which is produced by

201 the Canadian-based company Convenience Group Inc (2015) (Figure 5B). Installation was

202 completed in September 2015. 


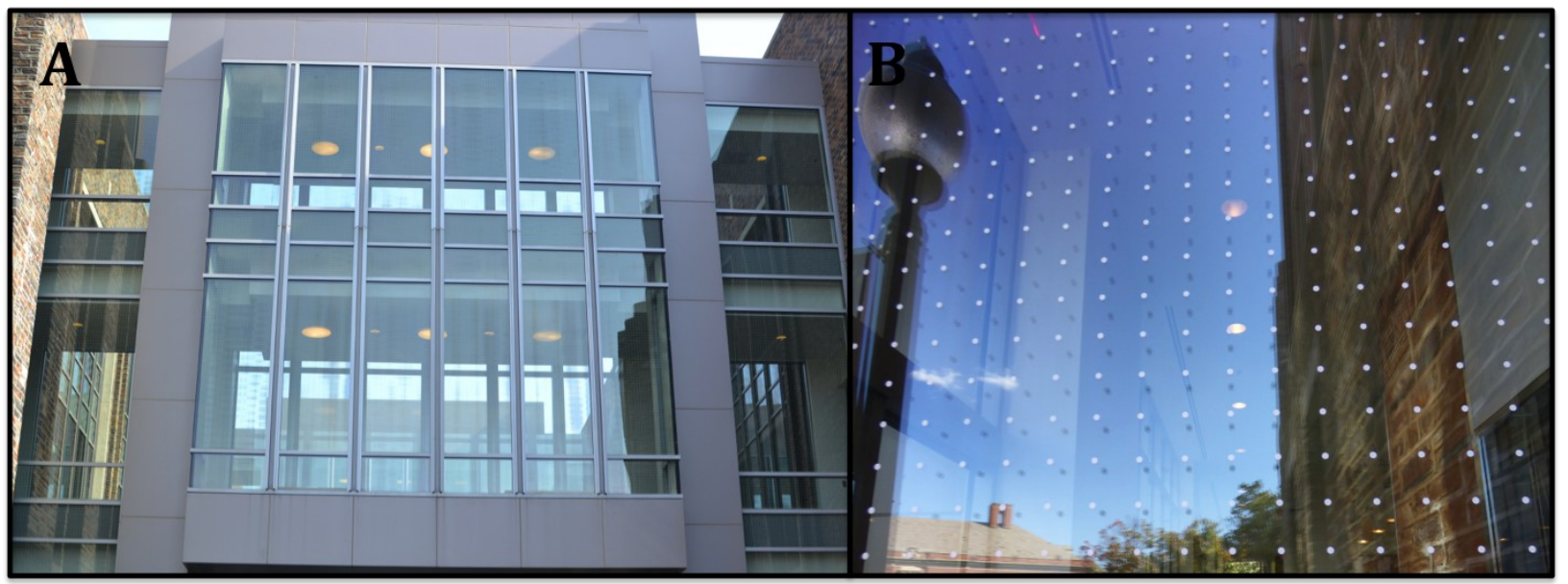

203 Figure 5. Bird deterrence dotted patterns on windows of Fitzpatrick building at Duke University. A:

204 Glass passageways. B: Close up of dotted pattern. Photos: Casey Collins.

\section{Discussion}

206 Building traits, glass, and surrounding area

207 Our results are consistent with those of previous studies documenting a positive relationship

208 between glass area and window collisions (Borden et al. 2010; Hager et al. 2013). Buildings on Duke

209 University's campus with more glass tended to cause more bird-window collisions. Fitzpatrick, the

210 building with the most window area, caused the most collisions. Schwartz and the Perk, the two

211 small buildings with small window areas, had the lowest collision frequencies.

212 The main exception to the correlation between glass area and collision frequency was at Penn, the

213 only building with fritted glass incorporated into the façade. Fritted glass is a feature known to deter

214 bird collisions (Klem 1990). Vertical frit lines cover approximately 30\% of Penn's windows (Figure

215 3D), which likely helps birds recognize the glass as a barrier mitigating collision incidence.

216 In addition to glass area, the habitat cover of areas surrounding buildings is also thought to have an

217 effect on the collision susceptibility (Hager et al. 2013). We found some anecdotal evidence that

218 surrounding area may be interacting with the glass effects we observed at Duke University's campus.

219 For example, Schwartz and the Perk not only have small glass area, but are also surrounded by a high 
proportion of impervious cover and relatively removed from wooded green spaces, which may have

221 further reduced their susceptibility to collisions. In contrast, Law Extension has a relatively high

222 percentage (39\%) of surrounding forest, which may have contributed to a high rate of collisions per

223 unit glass area. If surrounding forest is an important risk factor for bird-window collisions, it makes

224 the relative scarcity of collisions detected at Penn particularly compelling. Not only is the façade of

225 Penn nearly completely made of glass, but the building is partially surrounded by old growth (100+

226 year-old) forest, which may further indicate the effectiveness of glass fritting in this case.

227 While the deadliest building, Fitzpatrick, has a moderate amount of surrounding forest cover (33\%),

228 we attribute the high total number of collisions it caused to two second-story transparent glass

229 passageways that connect wings of the building (Figure 5A). While we did not specifically record

230 collision victims from beneath glass passageways, we began to notice that they were a likely site for

231 finding carcasses as we conducted surveys. This observation is consistent with other studies that

232 have implicated glass tunnels as architectural features associated with high incidence of window

233 collisions (Agudelo-Álvarez et al. 2010; Klem 1989).

234 We noticed a predominance of glass in buildings that are LEED ${ }^{\mathrm{TM}}$ certified, which could make these

235 "green" buildings especially deadly to birds. Both Fitzpatrick and Penn are certified at the Silver level

236 and have significant amounts of glass (Table 2). Although LEED ${ }^{\mathrm{TM}}$ certified buildings have the

237 potential to be more dangerous for birds (due to high glass area), solutions to prevent collisions

238 could be incorporated as part of the certification process. American Bird Conservancy has already

239 advocated for a LEED credit to prevent window collisions (US Green Buildings Council 2011) but we

240 encourage more research on the impact of the certification on collisions, and recommend this issue

241 be weighted more heavily in the certification scheme.

242 Seasonality

243 From our year-round campus-wide incidental collision data, we observed a trend of higher bird-

244 window collisions during spring and fall migration, especially during September and October 
245 (Figure 3). On a campus in Ohio, where similar research took place, 90\% of deaths by collisions also

246 occurred during migration (Borden et al. 2010). We confirm that standardized surveys during peak

247 migration, as proposed by Hager \& Cosentino (2014), is an efficient way of gathering collision data.

248 We recommend augmentation of their survey method by adding a spring survey to the protocol

249 because it improves chances to detect some species that may be missed in the fall due to differences

250 in migratory behaviors in the two seasons.

251 Species vulnerability

252 Although collisions occur year-round and can impact a wide range of bird species, migratory species 253 appear to be particularly vulnerable (Blem \& Willis 1998; Borden et al. 2010; Klem 2009a). Our

254 data supports the idea that migratory birds are especially susceptible to window-collision mortality,

255 as we found that $76 \%$ of the species recorded during carcass surveys were migratory and an

256 additional 9\% were partially migratory. One migratory species, Cedar Waxwing, was involved in

257 more collisions than any other species, accounting for $17 \%$ of the total collisions detected during

258 surveys. Cedar Waxwing is a gregarious species during migration (Sibley 2003) and when collisions

259 occurred, we found several individuals simultaneously. This species may be particularly vulnerable

260 to collisions because of the consumption of fermented berries that can cause ethanol toxicosis

261 affecting the bird's flight and sense of orientation (Fitzgerald et al. 1990). The second most common

262 collision victim on Duke University campus, the Ovenbird, is listed by many studies of bird-window

263 collisions as one of the most frequently encountered species (Blem \& Willis 1998; Borden et al.

264 2010; Cusa et al. 2015; Hager et al. 2008). The Ovenbird is an understory specialist, a guild which

265 has been identified as highly vulnerable to collisions (Blem \& Willis 1998).

266 The non-migratory species we most frequently observed as collision victims were Northern Cardinal

267 and Tufted Titmouse. Other studies have noted the pattern that migrants collide most frequently

268 during migration, whereas permanent residents are at risk of collision year-round (Blem \& Willis

269 1998). 
271 The combination of sound scientific data, media coverage, and a resolution supported by

272 representatives of more than 8000 students (approximately half of the total student body), led Duke

273 University to take action to mitigate bird deaths on campus (Figure 5). Scientific data allowed us to

274 identify problem buildings and prioritize windows for retrofitting treatment. Media coverage helped

275 communicate a local problem to a wider audience, and contributed to convincing the university to

276 take action. The GPSC resolution helped us reach high level administrators, which may have

277 otherwise been insulated from this issue. An additional research project we participated in allowed

278 us to put Duke University's collision data in context. A collaboration led by Hager and Cosentino

279 aimed to evaluate the drivers of bird-window collisions in North America at 40 university campuses.

280 Duke University was the campus with the highest collision frequency (unpublished data), which

281 contributed to our call to action.

282 Conservation biology is described as a 'crisis science' (Soulé 1985), but all too often biological

283 research ends for the scientist at the publication stage and crises remain unsolved. Here, we have

284 presented a rare example of conservation research that progressed almost immediately from data

285 collection to mitigation. We caution that action did not happen serendipitously, but rather we

286 engaged with decision makers and communicated with the media. This required effort beyond the

287 scope of the standard research life cycle, but we encourage other researchers, particularly those in

288 conservation biology, to follow our example and engage media, peers, and decision-makers to

289 resolve the crises being studied.

290 Recommendations

291 Bird-window collision studies have looked at patterns of presence and frequency of collisions as a

292 snap-shot, but research that compares time of collision, different seasons, years, or even decades are

293 still lacking. We recommend collision surveys that collect data over migratory and non-migratory

294 seasons, and for consecutive years. Another factor that has been overlooked in the analysis of 
295 collisions patterns is the weather. From studies about migration, we know that bird movements can 296 be affected by the weather (Richardson 1990), yet we still ignore how it can affect the frequency of 297 bird-window collisions.

298 Monitoring the effectiveness of bird deterrent materials is fundamental to management of buildings 299 and their effect on wildlife. Additionally, testing these materials at the building scale and evaluating 300 the effectiveness of UV-reflective materials is still needed. When available, placing camera traps near 301 windows might help with documenting the timing of collisions, as well as mapping exact locations of 302 collision events to better inform prevention.

\section{Acknowledgements}

304 We thank the many Duke University graduate and undergraduate students who assisted with data 305 collection for this project, especially the Wildlife Surveys class at the Nicholas School of the 306 Environment. We also thank the many volunteers around campus who have collected data for the 307 collision project since 2013, especially Anna Wilson. John Gerwin of the North Carolina Museum of 308 Natural Sciences assisted by receiving all bird carcasses we collected. We thank the 2014-2015

309 General Assembly of the Graduate and Professional Student Council for unanimously passing our 310 bird-window collisions resolution. Duke University Facilities and Management Department deserves 311 credit for its willingness to understand our study and take action on behalf of campus birds by 312 retrofitting Fitzpatrick.

\section{Data availability}

314 All data used for this publication can be made available, upon reasonable request, by the 315 corresponding author.

\section{References} ventanales en un campus universitario de Bogotá, Colombia. Ornitología Colombiana 10:310 . 
320

321

322

323

324

325

326

327

328

329

330

331

332

333

334

335

336

337

338

339

340

341

342

343

344

345

346

347

348

349

350

351

352

353

354

355

356

357

358

359

360

361

362

363

364

365

366

367

368

369
Arnold TW, and Zink RM. 2011. Collision mortality has no discernible effect on population trends of North American birds. Plos One 6:e24708.

Blem C, and Willis B. 1998. Seasonal variation of human-caused mortality of birds in the Richmond area. The Raven 69:3-8.

Borden WC, Lockhart OM, Jones AW, and Lyons MS. 2010. Seasonal, taxonomic, and local habitat components of bird-window collisions on an urban university campus in Cleveland, $\mathrm{OH}$. The Ohio Journal of Science 110:44-52.

Campus Sustainability Committee. 2015. Buildings, Duke sustainability. Available at https://sustainability.duke.edu/campus initiatives/buildings/ (accessed 6/15/2015).

Convenience Group Inc. 2015. Feather Friendly Bird Deterrent Technology (accessed 9/25 2015).

Cornell Lab of Ornithology. 2015. All about birds: species factsheets (accessed 6/24 2015).

Cusa M, Jackson DA, and Mesure M. 2015. Window collisions by migratory bird species: urban geographical patterns and habitat associations. Urban Ecosystems:1-20.

DeSante DF, D. R. Kaschube, and Saracco JF. 2015. Vital Rates of North American Landbirds. Available at www.VitalRatesOfNorthAmericanLandbirds.org (accessed 6/15/2015).

Duke University Facilities Management Department. 2012. Aerial imagery of Duke University. United States: Duke University.

Fitzgerald S, Sullivan J, and Everson R. 1990. Suspected ethanol toxicosis in two wild cedar waxwings. Avian Diseases 34:488-490.

Gelb Y, and Delacretaz N. 2006. Avian window strike mortality at an urban office building. The Kingbird 56:190-198.

Hager SB, and Cosentino BJ. 2014. Surveying for bird carcasses resulting from window collisions: a standardized protocol. PeerJ PrePrints 2:e406v401.

Hager SB, Cosentino BJ, and McKay KJ. 2012. Scavenging affects persistence of avian carcasses resulting from window collisions in an urban landscape. Journal of Field Ornithology 83:203211.

Hager SB, Cosentino BJ, McKay KJ, Monson C, Zuurdeeg W, and Blevins B. 2013. Window area and development drive spatial variation in bird-window collisions in an urban landscape. Plos One 8:e53371.

Hager SB, and Craig ME. 2014. Bird-window collisions in the summer breeding season. PeerJ 2:e460. Hager SB, Trudell H, McKay KJ, Crandall SM, and Mayer L. 2008. Bird density and mortality at windows. The Wilson Journal of Ornithology 120:550-564.

Klem D. 1989. Bird window collisions. The Wilson Bulletin 101:606-620.

Klem D. 1990. Collisions between birds and windows: mortality and prevention Journal of Field Ornithology 61:120-128.

Klem D. 2009a. Avian mortality at windows: The second largest human source of bird mortality on earth. In: T. D. Rich CA, D. Demarest, and C. Thompson, editor. Tundra to Tropics: Proceedings of the Fourth International Partners in Flight Conference. McAllen, Texas, USA: Partners in Flight. p 244-251.

Klem D. 2009b. Preventing bird-window collisions. The Wilson Journal of Ornithology 121:314-321.

Klem D. 2014. Landscape, legal, and biodiversity threats that windows pose to birds: A review of an important conservation issue. Land 3:351-361.

Klem D, and Saenger PG. 2013. Evaluating the effectiveness of select visual signals to prevent birdwindow collisions. The Wilson Journal of Ornithology 125:406-411.

Loss SR, Marra PP, and Will T. 2015. Direct mortality of birds from anthropogenic causes. Annual Review of Ecology, Evolution, and Systematics 46.

Loss SR, Will T, Loss SS, and Marra PP. 2014. Bird-building collisions in the United States: Estimates of annual mortality and species vulnerability. The Condor 116:8-23.

Richardson WJ. 1990. Timing of Bird Migration in Relation to Weather: Updated Review. In: Gwinner E, ed. Bird Migration: Springer Berlin Heidelberg, 78-101. 
370
Robbins CS, Sauer JR, Greenberg RS, and Droege S. 1989. Population declines in North American birds that migrate to the Neotropics. Proceedings of the National Academy of Sciences 86:7658-7662.

Sibley D. 2003. The Sibley field guide to birds of eastern North America. United States: Chanticleer Press and Alfred A. Knopf, Inc.

Soulé ME. 1985. What is conservation biology? A new synthetic discipline addresses the dynamics and problems of perturbed species, communities, and ecosystems. BioScience 35:727-734.

Ueda K, Belmonte J, Shepard A, Leary P, and Loarie S. 2015. iNaturalist (accessed 9/2014 2014).

US Environmental Protection Agency. 2013. EnviroAtlas - Meter Resolution Urban Area Land Cover Map for Durham, NC (2010). In: Laboratory UEOoRaDNER, editor. Research Triangle Park, NC.

US Green Buildings Council. 2011. Pilot Credit 55: Bird collisions deterrence. LEED Pilot Credit Library. United States. 